\title{
Reactivity to Oxidation of Metal Nanopowders after Electron Irradiation
}

\author{
Esen Dilmukhambetov ${ }^{1}$, Tilektes Espolov ${ }^{1}$, Madina Ospanova ${ }^{1} \&$ Alexander Ilyin ${ }^{2}$ \\ ${ }^{1}$ Kazakh National Agrarian University, Almaty, Kazakhstan \\ ${ }^{2}$ National Research Tomsk Polytechnic University, Tomsk, Russia \\ Correspondence: Madina Ospanova, Kazakhstan-Japan Innovation Centre, Kazakh National Agrarian University, \\ Abay av. 8, Almaty, 050010 Kazakhstan. Tel: 7-727-262-0182.E-mail: amazing_2007@mail.ru
}

$\begin{array}{lc}\text { Received: November 2, } 2012 & \text { Accepted: November 22, } 2012 \quad \text { Online Published: December } 28,2012 \\ \text { doi:10.5539/jmsr.v2n1p175 } & \text { URL: http://dx.doi.org/10.5539/jmsr.v2n1p175 }\end{array}$

\begin{abstract}
The nanopowders of iron, nickel, molybdenum and copper received by electric explosion of wire were irradiated by an electron current on the liner electron accelerator with the radiation doses of 1, 5, $10 \mathrm{Mrad}$. The differential thermal and X-ray analyses were used to determine the effect of electron irradiation on metal nanopowders. Four parameters of activity of nanopowders were evaluated according to the differential thermal analysis: the initial temperature of oxidation, the completeness of oxidation, the maximum speed of metal oxidation and the thermal effect of oxidation. It was ascertained that the thermal effect of combustion increased after irradiation by $1.5-2.5$ times. It was shown that the significant increase of the heat of combustion of nanopowders was caused by the increase of the internal stored energy as a result of the ionizing effect of electrons. The electrostatic model of surface charged structures of nanoparticles generated by the ionizing effect of electrons was offered, and its analogue is a spherical capacitor. This model makes it possible to estimate the increase of the surface energy of nanopowders by charging the spherical nanocapacitor with 110-1100 kJ/mol. Studies conducted on the X-ray analyzer have shown that the lattice parameters of the initial and irradiated metal nanopowders are greater than those of the standard samples of massive metals. Irradiation of nanopowders by accelerated electrons furthers stabilization of interplanar spacings of crystal lattices and brings them closer the standard of massive metals.
\end{abstract}

Keywords: nanopowders, electron irradiation, the thermal effect, the crystal lattice, energy condensed systems, nanocapacitor

\section{Introduction}

In the present time nanodimensional metal powders are regarded as perspective components for preparation energetic condensed systems: explosive materials, rocket fuel and pyrotechnical compositions (Gromov et al., 2006; Teipel, 2004; Yagodnikov, 2009). In this respect nanopowders (NP) received by electric explosion of wire in the inert gas environment are of considerable interest (Iliyn, 2001; Wu et al., 2010). The peculiarity of these nanopowders is their heightened energy capacity that appears during the processes of combustion, explosion and detonation (Lerner et al., 2009; Nazarenko, 2005). Formation of energy saturated structures inside these particles occurs on the stage of electroexplosive production of nanopowders. The stored energy of these structures is preserved for a long time in dry atmosphere (Iliyn et al., 2009).

The studies of the effect of different types of radiation on massive materials (metals, concrete, ceramics, composites, etc.) are the wide area of modern radiation chemistry (Rutherford et al., 2007; Was et al., 2007). In recent years new directions in this field of research have appeared which deal with the effect of radiation on materials in nanodimensional state (Sickafus et al., 2007). The study (Rong et al., 2002) shows that irradiation of polymer composites with implanted metal nanoparticles furthers improvement of their optical and thermal properties. The research (James et al., 2009) discovered that the effect of X-rays on metal nanopowders implanted in cancer destructs a tumor as a result of local warming. This research makes it possible to treat cancer by local hypothermia. The work of Gromov (Gromov et al., 2007) shows the influence of electromagnetic radiation of the optical range on metal nanoparticles inside the polymer matrix. It was discovered that radiation caused heating of nanoparticles that initiated phase transition of the polymer matrix. 
The aim of this work is the analysis of the influence of irradiation by accelerated electrons on parameters of oxidation activity and characteristics of crystal lattices of energysaturated metal nanopowders.

\section{Materials and Research Methods}

During this study we used nanopowders of iron, nickel, molybdenum and copper received by electric explosion of wire in the argon environment on the equipment (installation, apparatus) UDP-4G at the Research Institute of High Tensions of Tomsk Polytechnic University. The particle sizes of nanopowders vary between 10 nanometers and several microns. Crystal structure determination and size measurements were done by the scanning electron microscope (SEM) JSM 6510 LA and transition electron microscope (TEM) JEM 1011(JEOL).

The initial nanopowders were irradiated by an electron beam with the energy of $4 \mathrm{MeV}$ and the radiation doses of 1, 5 and $10 \mathrm{Mrad}$ on the electron accelerator ELU-4 at al-Farabi Kazakh National University.

The crystal lattice parameters of the initial and irradiated nanopowders were determined by the X-ray diffractometer DRON-4.

The chemical activity of metal nanopowders was measured by the method of differential thermal analysis (DTA) on SDT Q600 in air environment. The software of the thermal analyzer makes it possible to determine the four parameters of chemical activity: the initial temperature of oxidation $\left(\mathrm{T}_{0},{ }^{\circ} \mathrm{C}\right)$, the completeness of oxidation $(\alpha$, mass \%), the maximum speed of metal oxidation $\left(\mathrm{V}_{\max }\right.$, mass \% $/ \mathrm{min}$.) and the specific thermal effect of oxidation $(\Delta \mathrm{H}, \mathrm{J} / \mathrm{g})$.

\section{Results and Discussion}

The microphotographs of metal nanopowders made on the scanning electron microscope show presence of round particles of micron size and particles of nanosize (Figure 1). Figure 2 shows the typical diagram of distribution of nanoparticles by their size. The analysis of the distribution of particles by their size demonstrates that the maximum of distribution corresponds to the particles with the size of 100-250 nm. The percentage concentration of nanoparticles with the size $100-250 \mathrm{~nm}$ was no less than $80 \%$.

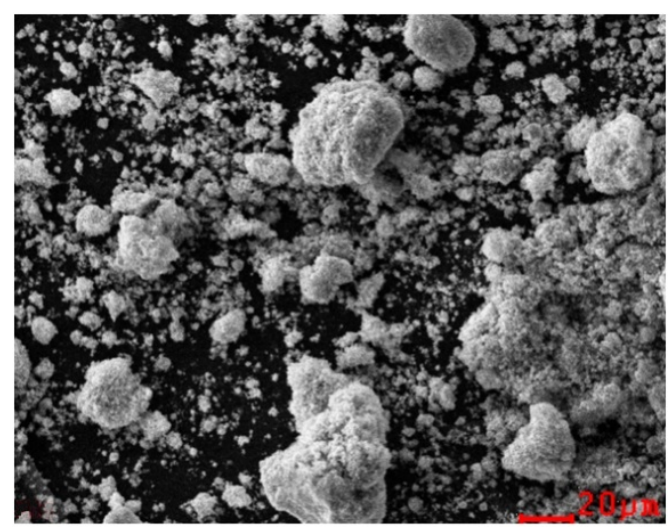

a)

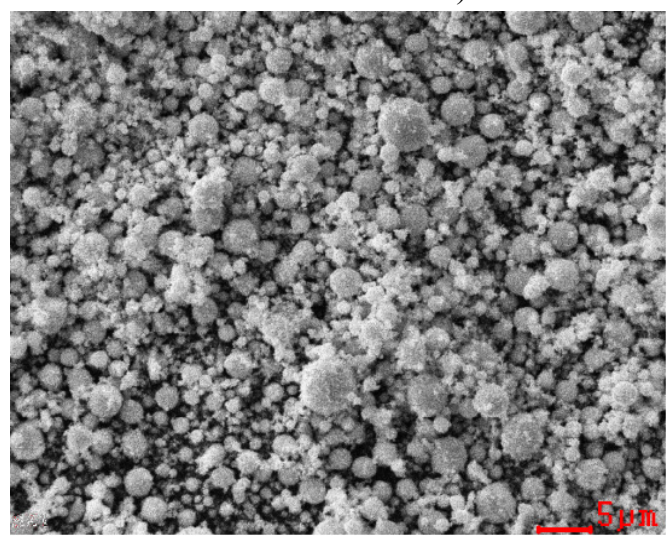

c)

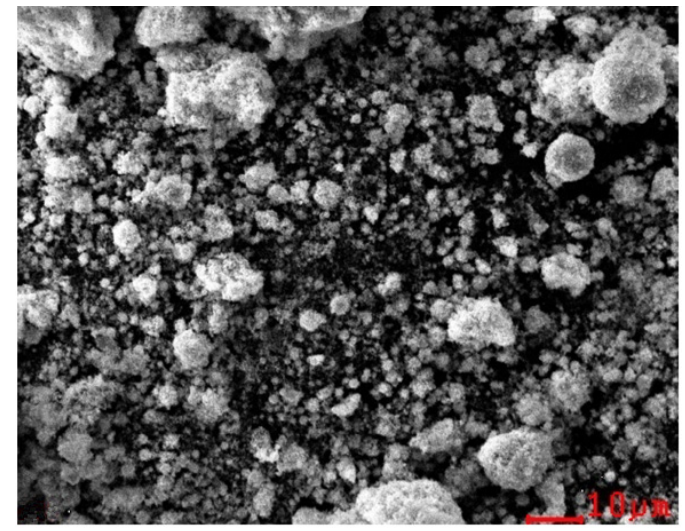

b)

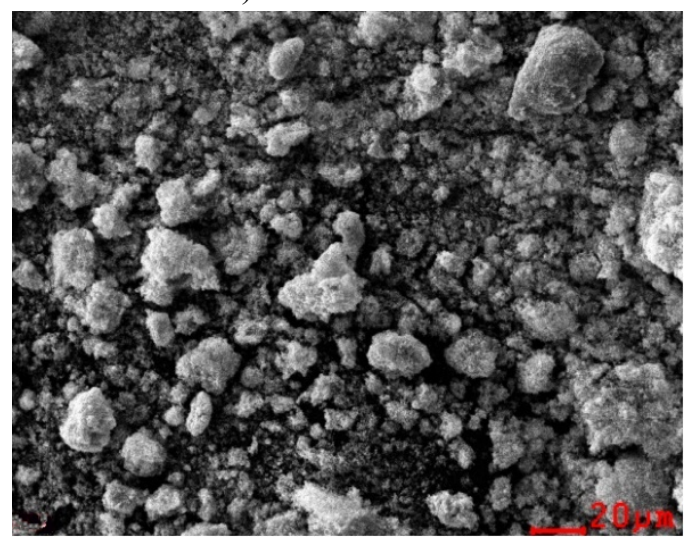

d)

Figure 1. Microphotography of metal nanopowders: a) -iron, b) -nickel c) -molybdenum and d) -copper 


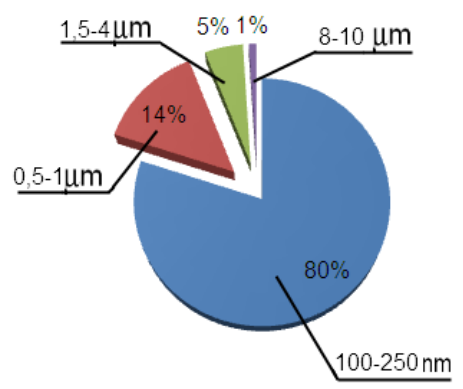

Figure 2. The diagram of distribution by the size of nanoparticles

Figures 3, 4 show the thermograms of oxidation of iron nanopowder before and after electron irradiation on the thermoanalyzer SDT Q600. The area under the thermal current curve equals numerically to the specific thermal effect of oxidation of nanopowders.

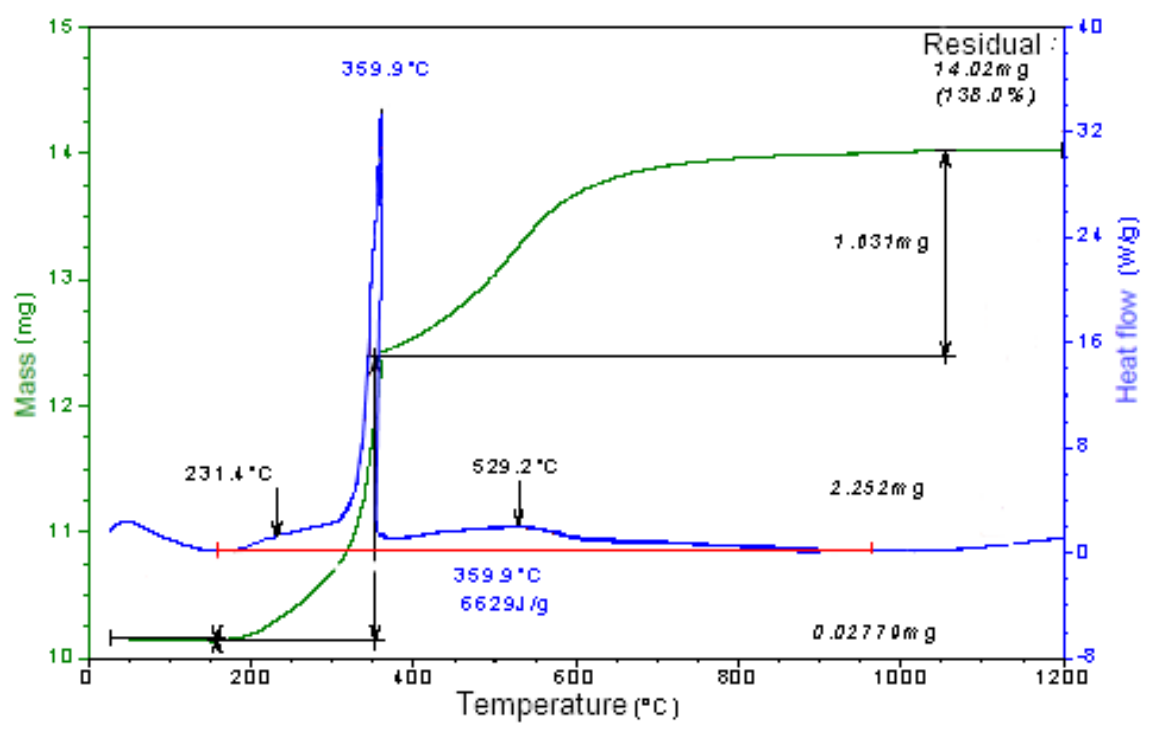

Figure 3. The thermogram of the initial iron nanopowder

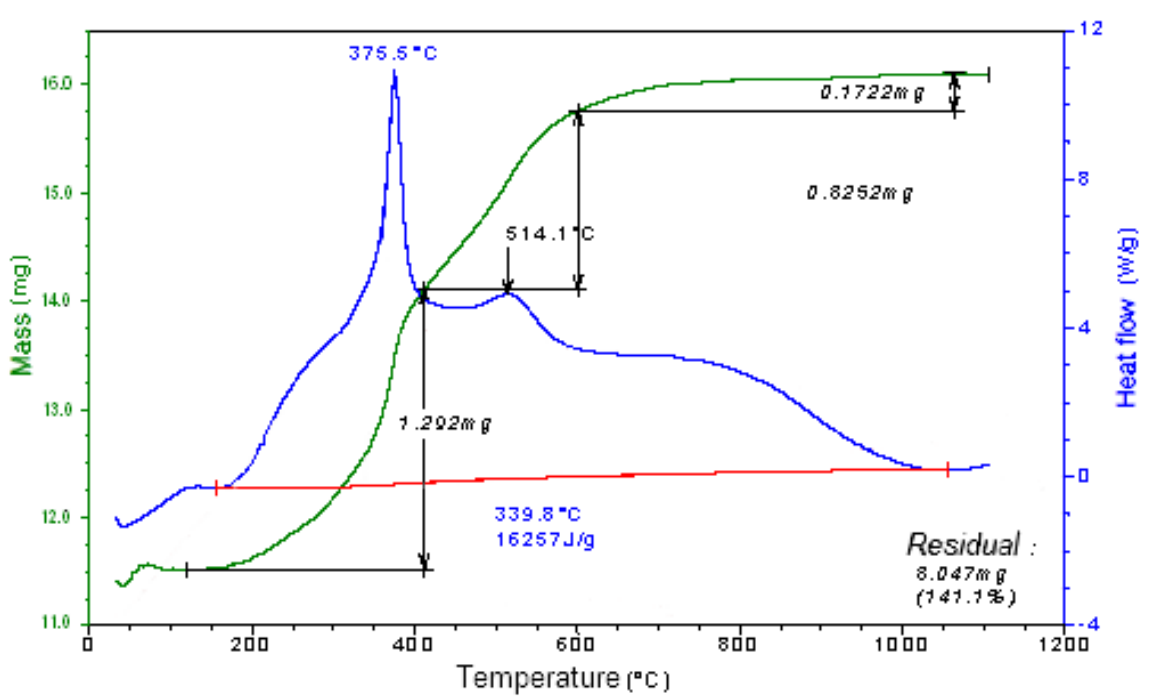

Figure 4. The thermogram of the iron nanopowder irradiated by the dose of $10 \mathrm{Mrad}$ 
The results of the thermogram analysis of metal nanopowders before and after electron irradiation are shown on Table 1. They characterize macroscopic effects caused by the electron irradiation. For example, the increase of the mass of nanopowder samples correspondents to the stoichiometry of formation of oxides. Irradiation of metal nanopowders by an electron beam does not influence significantly on the initial temperature of oxidation. The temperature variations for all irradiated samples were 10 degrees. The maximum oxidation rate decreases with the increase of radiation dose almost for all nanopowders with the exception of the molybdenum nanopowder. The completeness of oxidation of irradiated NP is usually higher than that of the initial (nonirradiated) NP. It should be noted that the completeness of oxidation never reaches $100 \%$ because of the oxide film covering the surface of metals. Electron irradiation of metal nanopowders reveals essentially in the significant increase of the thermal effect of oxidation of metals. For example, the specific thermal effect of oxidation of iron nanopowder irradiated by the dose of $10 \mathrm{Mrad}$ is 2.5 times more than that of the initial nanopowder. These results indicate considerable amount of stored energy in the irradiated nanopowders.

Table 1 . The parameters of oxidation activity of metal nanopowders

\begin{tabular}{|c|c|c|c|c|c|c|}
\hline \multirow{2}{*}{ The samples of nanopowders- } & \multicolumn{2}{|c|}{ The sample mass, mg } & \multirow[t]{2}{*}{$T_{o},{ }^{\circ} \mathrm{C}$} & \multirow[t]{2}{*}{$V_{\max }, \mathrm{mg} / \mathrm{s}$} & \multirow[t]{2}{*}{$\alpha, \%$} & \multirow[t]{2}{*}{$\Delta H, \mathrm{~J} / \mathrm{g}$} \\
\hline & initial & after DTA & & & & \\
\hline Nanopowder of Fe & 10.1 & 14.0 & 160 & 0.033 & 96.69 & 6629 \\
\hline NP Fe(1 Mrad) & 9.4 & 13.2 & 150 & 0.020 & 98.15 & 13429 \\
\hline NP Fe (5 Mrad) & 10.5 & 14.6 & 150 & 0.016 & 96.88 & 13061 \\
\hline NP Fe (10 Mrad) & 11.4 & 16.0 & 160 & 0.010 & 97.96 & 16257 \\
\hline Nanopowder of Ni & 10.0 & 12.5 & 160 & 0.013 & 98.03 & 8128 \\
\hline NP Ni (1 Mrad) & 11.2 & 14.2 & 160 & 0.008 & 99.14 & 10544 \\
\hline NP Ni (5 Mrad) & 12.5 & 15.5 & 160 & 0.009 & 97.59 & 10357 \\
\hline NP Ni (10 Mrad) & 9.6 & 11.9 & 170 & 0.008 & 97.56 & 11555 \\
\hline Nanopowder of Mo & 10.5 & 15.2 & 175 & 0.038 & 96.53 & 6673 \\
\hline NP Mo (1 Mrad) & 9.7 & 13.8 & 175 & 0.050 & 95.55 & 6272 \\
\hline NP Mo (5 Mrad) & 11.5 & 16.9 & 175 & 0.025 & 98.49 & 7851 \\
\hline NP Mo (10 Mrad) & 9.5 & 13.6 & 175 & 0.017 & 95.31 & 7010 \\
\hline Nanopowder of $\mathrm{Cu}$ & 10.4 & 12.6 & 165 & 0.013 & 96.11 & 1473 \\
\hline NP Cu (1 Mrad) & 9.4 & 11.1 & 170 & 0.006 & 94.56 & 1580 \\
\hline $\mathrm{NP} C u$ (5 Mrad) & 8.9 & 10.7 & 165 & 0.005 & 95.73 & 2848 \\
\hline NP Cu (10 Mrad) & 9.7 & 11.9 & 150 & 0.005 & 97.82 & 2823 \\
\hline
\end{tabular}

The thermodynamics specific heat of combustion of metals with formation of oxides is given below for comparison: $\mathrm{FeO}-4728 \mathrm{~J} / \mathrm{g}, \mathrm{Fe}_{2} \mathrm{O}_{3}-7341 \mathrm{~J} / \mathrm{g}, \mathrm{NiO}-4083 \mathrm{~J} / \mathrm{g}, \mathrm{MoO}_{2}-6136 \mathrm{~J} / \mathrm{g}, \mathrm{Cu}_{2} \mathrm{O}-1351.6 \mathrm{~J} / \mathrm{g}, \mathrm{CuO}-2$ $534.25 \mathrm{~J} / \mathrm{g}$. The significant increase of the thermal effect of oxidation of nanopowders indicates that part of electron beam energy is transferred by metal nanoparticles and accumulated in their internal structures.

The products of combustion of metal powders - oxides- were measured by an electron microscope. Figure 5 shows microphotographs of the initial iron particles and their oxidation products under a transmission electron microscope. It is obvious from the picture a cake mass an oxide consisting as a collection an agglomerates form during combustion. Some separate particles of metal oxides could be seen inside these agglomerates within wide size by hundredth order of magnitude. Thus high combustion temperatures further aggregation of caked particles of oxidation products. 


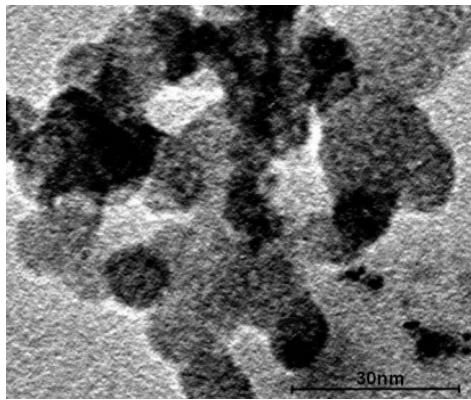

a)

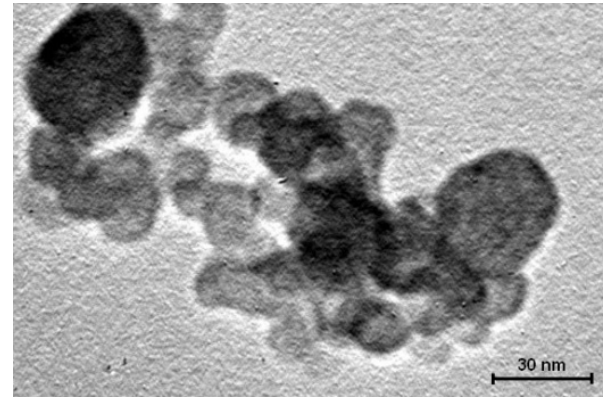

b)

Figure 5. Microphotographs of an iron nanopowder: a) - before oxidation and b) - after oxidation

The X-ray analyses points out changes in the internal structures of nanopowders. Tables 2-3 illustrate the changes in the interplanar spacings of crystal lattices of nanopowders with the maximum thermal energy. The interplanar spacings of iron and molybdenum standards with body-centered cubic lattices and the interplanar spacings of nickel and copper standards with face-centered cubic lattices are shown for comparison. According to the results of X-ray analysis the electron irradiation decreases interplanar spacings in crystal lattices of metal nanoparticles as compared with nonirradiated samples of nanopowders. The values of interplanar spacings of irradiated nanopowders verge towards the values of standard samples of massive metal.

The apparent effect of the significant increase of the thermal effect of oxidation of metal nanopowders as a result of irradiation requires more detailed discussion. It is known that the electron irradiation according to the character of its influence on substances is regarded as an ionizing type of radiation (Kurt et al., 2007). The electron radiation with the energy of $4 \mathrm{MeV}$ meets the criteria of ionizing radiation.

Table 2. The interplanar spacings of initial and irradiated iron and molybdenum nanopowders with BCC-lattice

\begin{tabular}{|c|c|c|c|c|c|c|}
\hline $\begin{array}{l}\text { Crystal plane } \\
(\mathrm{h} \mathrm{k} \mathrm{l)}\end{array}$ & $\mathrm{Fe}, \AA$ & $\begin{array}{l}\mathrm{Fe} \\
(10 \mathrm{Mrad}), \AA\end{array}$ & $\begin{array}{l}\text { Standar } \\
\mathrm{Fe}, \AA\end{array}$ & Mo, $\AA$ & $\begin{array}{l}\text { Mo } \\
(5 \mathrm{Mrad}), \AA\end{array}$ & Standard Mo, $\AA$ \\
\hline (110) & 2.055 & 2.026 & 2.010 & 2.254 & 2.238 & 2.225 \\
\hline (200) & 1.435 & 1.433 & 1.430 & 1.576 & 1.578 & 1.574 \\
\hline (211) & 1.173 & 1.171 & 1.170 & 1.286 & 1.289 & 1.285 \\
\hline (220) & 1.011 & 1.011 & 1.010 & 1.114 & 1.113 & 1.113 \\
\hline
\end{tabular}

Table 3. The interplanar spacing for initial and irradiated nickel and copper nanopowders with FCC-lattice

\begin{tabular}{lllllll}
\hline $\begin{array}{l}\text { Crystal plane } \\
(\mathrm{h} \mathrm{k} \mathrm{l})\end{array}$ & $\mathrm{Ni}, \AA$ & $\begin{array}{l}\mathrm{Ni} \\
(10 \mathrm{Mrad}), \AA\end{array}$ & $\begin{array}{l}\text { Standar } \\
\mathrm{Ni}, \AA\end{array}$ & $\mathrm{Cu}, \AA$ & $\begin{array}{l}\mathrm{Cu} \\
(5 \mathrm{Mrad}), \AA\end{array}$ & Standard Cu, $\AA$ \\
\hline$(111)$ & 2.047 & 2.036 & 2.030 & 2.115 & 2.089 & 2.080 \\
$(200)$ & 1.764 & 1.766 & 1.760 & 1.803 & 1.804 & 1.810 \\
$(220)$ & 1.245 & 1.246 & 1.240 & 1.280 & 1.279 & 1.280 \\
$(311)$ & 1.064 & 1.063 & 1.060 & 1.090 & 1.088 & 1.090 \\
$(222)$ & 1.015 & 1.014 & 1.020 & 1.044 & 1.044 & 1.040 \\
\hline
\end{tabular}

The main influence of an electron beam on nanopowders reveals as excitation and ionization of atoms without any structural changes in their crystal lattices. The generated excess positive charge of the ions of metals concentrates near the surface and is neutralized by the negative charge of the surface oxide layer. In this case the particles of the nanopowder can be represented as a spherical capacitor if disregarding the chemical nature of metals. The simple model of a spherical capacitor is very convenient for estimation of stored surface energy of nanopowders. This stored energy is mainly of electrostatic nature.

The excess energy accumulated in nanopowders in the process of irradiation represents the work at charging a 
spherical capacitor.

$$
-d W=c^{-1} q d q=\frac{R-r}{4 \pi \varepsilon \varepsilon_{0} R r} q d q
$$

the $c$ - capacity of the spherical capacitor, $R$ - radius of the external sphere, $r$ - radius of the internal sphere, $q-$ charge of the capacitor, $\varepsilon_{0}$ - electric constant, $\varepsilon$ - relative permeability. The external sphere covers the oxide surface of powder particles, the internal sphere - the metal particles (Tribus, 1970).

The stored energy of iron nanoparticles with the radius of the outer sphere $100 \mathrm{~nm}$ and the thickness of the oxide layer $5 \mathrm{~nm}$ can be estimated as the work at charging a spherical capacitor. The typical value of the relative permeability of metal oxides is 7-30. If the part of the single-ionized metal atoms in the particle of the nanopowder is $10^{-4}-10^{-3}$, the internal energy of the nanoparticle will increase at about $110-1100 \mathrm{~kJ} / \mathrm{mol}$ per a unit of elementary electric charge when $\varepsilon$ equals 20 . These energy values are in the same range as the enthalpy of formation of metal oxides are. During the combustion of nanopowders a great amount of surface electrostatic energy received by the metal nanoparticles after their irradiation makes an additional contribution to the combustion value.

\section{Conclusion}

The oxide activity of saturated nanopowders of iron, nickel, molybdenum and copper received by the electroexplosive method was analyzed after their electron irradiation:

1) It was determined that electron irradiation of nanopowders with the doses of 1, 5, 10 Mrad furthers accumulation of stored energy, which is released in the processes of oxidation and combustion.

2) The specific thermal effect of oxidation of nanopowders increases at $1.2-2.5$ times as a result of electron irradiation.

3) The interplanar spacings of crystal lattices of irradiated nanopowders as compared with non-irradiated ones decrease and verge towards the interplanar spacings of massive metal standards.

4) The electrostatic model of increase of the internal energy of nanopowders received by ionizing influence of electron irradiation was offered.

\section{References}

Gromov, A. A., Förter-Barth, U., \& Teipel, U. (2006). Aluminum nanopowders produced by electrical explosion of wires and passivated by non-inert coatings: Characterization and reactivity with air and water. J. Powder Tech., 164, 111-115. http://dx.doi.org/10.1016/j.powtec.2006.03.003

Gromov, A. A., \& Richardson, H. H. (2007). Generating heat with metal nanoparticles. J. Nano Today, 2(1), 30-38 (in Russian).

Iliyn, A. P. (2001). About activity of aluminum powders. Physics of Combustion and Explosion, 37(4), 58-62 (in Russian).

Iliyn, A. P., Korshunov, A. V., \& Tolbanova, L. O. (2009). Structure, properties and problems in certification of metal nanopowders. Bulletin of the Tomsk Polytechnic University, 314(3), 35-40 (in Russian).

James, F. H., \& Daniel, N. S. (2009). Patent application title: Methods of enhancing radiation effects with metal nanoparticles. NanoProbes, Inc., Patent application number: 20090186060

Kurt, E. S., Eugene, A. K., \& Blas, P. U. (2007). Radiation Effects in Solids. NATO Science Series, 235. http://dx.doi.org/10.1007/978-1-4020-5295-8

Lerner, M. I., Svarovskaya, N. V., Psahiye, S. G., \& Bakina, O. V. (2009). Technology of obtaining, features, and some uses of electroexplosive metal nanopowders. Russian Nanotechnology, 4(11-12), 56-68 (in Russian).

Nazarenko, O. B. (2005). Electroexplosive nanopowders: Preparation, properties and application (pp. 148-152). Tomsk: Pub. TSU (in Russian).

Rong, M. Zh., Zhang, M. Q., Wang, H. B., \& Zeng, H. M. (2002). Surface modification of magnetic metal nanoparticles through irradiation graft polymerization. J. Applied Surface Science, 200, 76-93. http://dx.doi.org/10.1016/S0169-4332(02)00620-7

Rutherford, A. M., \& Duffy, D. M. (2007). The effect of electron-ion interactions on radiation damage simulations. J. Phys.: Condens. Matter, 19, 1-9. http://dx.doi.org/10.1088/0953-8984/19/49/496201

Sickafus, K. E., Kotomin, E. A., \& Uberuaga, B. P. (2007). Radiation Effects in Solids. NATO Science Series, 
235. http://dx.doi.org/10.1007/978-1-4020-5295-8

Teipel, U. (2004). Energetic Materials. Wiley. http://dx.doi.org/10.1002/3527603921

Tribus, M. (1970). Thermostatic and Thermodynamics (504). New Jersey: D.Van Nostrand Company.

Wu, Y., Hao, S., Yang, Y., Wang, M., \& Deng, J. (2010). Electrical Explosion of Wires Applying in Nanometer Materials Preparation. J. Pulsed Power Applications, 505-507.

Was, Gary S. (2007). Fundamentals of Radiation Materials Science. Springer, 827. http://dx.doi.org/10.1007/978-3-540-49472-0

Yagodnikov, D. A. (2009). Ignition and combustion of powdered metals. M: Publ. MSTU. N.E. Bauman (in Russian). 